\title{
Riera i Melis, A. (2019). "Un regne dins en la mar". Estudis sobre l'economia, la societat i la fiscalitat de Mallorca a la baixa edat mitjana. Lleida: Pagès Editors. 366 pp. ISBN: 978-84-1303-186-6
}

Author:

Antoni Mas Forners

Universitat de les Illes Balears (Spain)

antoni.mas@uib.cat

https://orcid.org/0000-0002-8451-2294

Date of reception: 27/07/21

Date of acceptance: 29/07/21

\section{Citation:}

Mas Forners, A. (2021). Book review: Riera i Melis, A. (2019).

"Un regne dins en la mar". Estudis sobre l'economia, la societat i la fiscalitat de Mallorca a la baixa edat mitjana. Anales de la Universidad de Alicante. Historia Medieval, (22), 393-396.

https://doi.org/10.14198/medieval.20556

(C) 2021 Antoni Mas Forners

Licence: This work is licensed under a Creative Commons Attribution 4.0 International License (CC BY 4.0).

\section{(c) (i)}

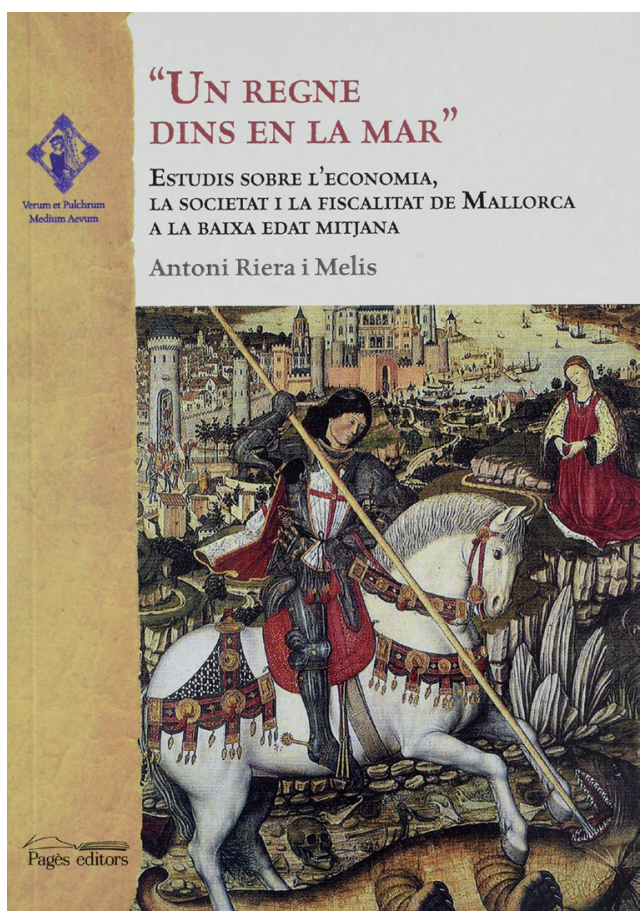

"Un regne dins en la mar". Estudis sobre l'economia, la societat i la fiscalitat de Mallorca a la baixa edat mitjana (col-lecció Verum et Pulcrum Medium Aevum, Pagès Editors), a cura de Flocel Sabaté i Maria Soler, consisteix en el primer recull d'estudis de l'historiador Antoni Riera Melis que es publica, a manera d'homenatge, de l'obra de l'historiador mallorquí.

El bessó de l'obra, constituit per una selecció dels treballs referits a la corona de Mallorca, va precedit de tot un seguit de pròlegs («Antoni Riera, historiador medievalista», a càrrec de Flocel Sabaté; «Antoni Riera i la Universitat de Barcelona, d'estudiant de filosofia i lletres a catedràtic d'història medieval», a càrrec de Maria Àngels Pérez Samper, «Bibliografia d'Antoni Riera i Melis», a càrrec de Maria Soler, i «Mallorca dins l'obra investigadora d'Antoni Riera i Melis, a càrrec de Pau Cateura». 
Tots aquest treballs permetran al lector de l'obra un coneixement acurat de la fecunda trajectòria intel-lectual i investigadora de l'historiador de Sant Llorenç.

Això, per altra part, ens permetrà estalviar-nos-hi les referències, tret de remarcar l'entitat dels treballs que han estat recollits en aquest volum:« El estatuto arancelario de los mallorquines en el seno de la Corona de Aragón en la segunda mitad del siglo XIII»; «La "Llicència per a barques" de 1284. Una font important per a l'estudi del comerç exterior mallorquí del darrer quart del segle XIII»; «Mallorca 12981311, un ejemplo de planificación econòmica en la época de plena expansión»; «La lezda balear de 1302, un punto de fricción entre el reino de Mallorca y las ciudades mercantiles catalanas a principio de siglo XIV»; «El regne de Mallorca en el context internacional de la primera meitat del segle XIV»; «Els jueus de Menorca a la primera meitat del segle XIV. Les seqüeles d'una relació d'identitats asimètrica.»

Quaranta anys després, els primers quatres articles (El estatuto arancelario...; La "Llicència per a barques"... ; Mallorca 1298-1311... ; La lezda .....) escrits entre 1977 i 1981, continuen essent bàsics per al coneixement de la història del regne i de la corona de Mallorca, sobretot des d'una perspectiva política, fiscal i comercial. Allò mateix es pot dir sobre el cinquè (El regne de Mallorca...), quelcom més recent (1989). Tots plegats, dèiem, són encara essencials per als interessats en aquests aspectes de la història del reialme de Mallorca i responen als mateixos patrons metodològics i estilístics, conjuminant una erudició i un maneig de les fonts que els han convertit en una referència ineludible, de manera que, conjuntament, han bastit un buc interpretatiu que encara ara es manté amb força.

El bessó d'aquests treballs respon a la voluntat d'estudiar el procés de formació i consolidació d'una monarquia -la de la Corona de Mallorca-, constituida per territoris de conquesta recent i de colonització encara en curs (el regne insular) i, a més, per territoris «vells», que no assoliren títol de Regne -ans el contrari, foren vinculats a d'altres entitats polítiques: a França, en el cas de Montpeller i a Catalunya, en el cas del Rosselló-. I això en el període comprès entre les acaballes del segle XIII i la primera meitat del segle XIV, en què aquesta monarquia -que Jaume I havia decidit que no tengués cap tipus de vinculació amb la branca major de la Corona d'Aragó- en passà a ser feudatària, com a conseqüència del tractat de Perpinyà (1279), que convertia Jaume II de Mallorca en vassall del seu germà Pere el Gran.

D'acord amb l'argumentació de Riera, la situació, ambigua i complexa, que es genera a partir d'aqueix tractat -que Jaume II hagué de subscriure ben a desgratesdevé la clau, no tan sols de les relacions entre totes dues monarquies, sinó encara, i més específicament, de la política que desenvoluparen Jaume II i els seus successors.

El primer bloc d'articles permet observar, gràcies a la mirada aguda i atenta de Riera Melis, en com es concretà un estat de coses el que, a partir de 1279, donà pas a dos punts de tensió recurrents: d'una banda, la voluntat, per part dels monarques 
catalano-aragonesos, d'actuar com a veritables senyors dels reis de Mallorca, tot involucrant-los, i amb ells als seus territoris, en afers que podien anar en contra dels interessos dels súbdits de la monarquia mallorquina i de la corona mateixa. Aqueixa subordinació als interessos de la branca major també tengué contrapartides, com el reconeixement dels privilegis aranzelaris concedits per Jaume I als habitants del regne de Mallorca -momentàniament returada amb motiu del conflicte francoaragonès de 1285-. I, d'altra banda, si el rei d'Aragó volia actuar com a veritable senyor dels seus territoris i dels de la branca menor, Jaume II i els seus successors estaven disposts a actuar com a veritables reis en els seus dominis, particularment en el regne de Mallorca. I per això calia -així es desprèn d'aquests treballs d'Antoni Riera- saber fins on podia arribar el poder efectiu -o l'autonomia- d'aqueixa branca menor, amb un estatus polític incert i fins i tot fluctuant, sempre mediatitzat per la major. Calia saber-ho, tot i que fos estirant la corda i tractant d'establir -infructuosament- una lleuda als súbdits directes de la Corona d'Aragó (qüestió objecte d'un dels acurats estudis del volum), però també amb iniciatives reeixides, i de tanta volada, com la creació del sistema monetari mallorquí, que s'han d'estudiar en el marc del conjunt de polítiques del segon període del regnat de Jaume II. Antoni Riera dedica a aqueixa qüestió un acuradíssim treball («Mallorca 1298-1311...) en què demostra que tot un seguit d'iniciatives del monarca mallorquí foren objectes d'una planificació comuna i amb una execució prevista, podem pensar que d'una manera ben simbòlica, just als inicis del segle XIV. Es tracta, fonamentalment, de l'esmentada creació del sistema monetari i de les Ordinacions per a la creació de noves viles o pobles (1300), però també dels inicis de la creació de consolats mercantils propis. En aqueix article Riera té el mèrit de ser el primer autor a estudiar detingudament les esmentades Ordinacions -que preveien la creació o promoció de noves poblacions, amb la mateixa amplada de carrers, cada una de cent veïns, amb un patrimoni idèntic (un solar, 3,5 ha de terra conreable i 7,1 de terres de garriga)- que adquirien el seu patrimoni d'una manera peculiar. Tal com para esment l'historiador mallorquí, els posseïdors de les terres afectades per l'esmentada normativa adquirien l'obligació de subestablir-les en emfiteusi als nous pobladors, a canvi de rendes que, tret del delme, consistien en censos en metàl-lic fixats en la nova moneda que creava Jaume II, cosa que, sens dubte, en volia facilitar la circulació. Es tractava, en paraules d'Antoni Riera, d'una reparcel-lació forçosa del domini útil d'extenses zones de l'illa que propiciaria el creixement de la producció. Tot això, acompanyat de la concessió de crèdits als nous pobladors que haurien de dur a terme els ja establerts i d'una moratòria en el pagament de deutes. Laplicació de les Ordinacions, com ja hem dit, facilitava l'altra gran iniciativa d'en Jaume II, també estudiada detingudament per Riera: la creació del sistema monetari mallorquí, que havia de substituir la moneda de curs legal -la valenciana- però també d'altres monedes foranes. La mesura que, com afirma Riera, també reforçava l'autonomia comercial i financera del regne respecte de la 
Corona d'Aragó, es començà a concretar amb l'encunyament de numerari el mateix 1300. Així i tot, l'equiparació artificial entre el real de Mallorca i el de València va provocar la devaluació del mallorquí, cosa que, així i tot, no va comprometre el caràcter de moneda legal del nou numerari. D'altres iniciatives no assoliren l'èxit previst -com l'intent de creació d'una manufactura llanera de qualitat mitjana a la Ciutat de Mallorca- o tot just s'iniciaren, com la política d'assoliment de consolats mercantils propis -només aconseguida a Bugia, a 1302-. Aquesta perspectiva de conjunt -referida només al regnat d'en Jaume II de Mallorca- es complementa amb l'article de síntesi «El regne de Mallorca en el context internacional de la primera meitat del segle XIV», publicat ja en a 1989, en el qual l'autor resumeix la seva visió sobre el reialme de Mallorca. I això tot indicant que «des del 1279, no era més que un conjunt de petits territoris de la "confederació" catalanoaragonesa, discontinus, administrats per un monarca que només hi gaudia d'una sobirania limitada, les estructures econòmiques, socials i polítiques dels quals no eren ni anàlogues ni complementàries.» Tanmateix, l'autor hi remarca que els «territoris integrants del regne de Mallorca», tot i les "paleses divergències estructurals, presentaven un seguit de trets comuns: llur caràcter marítim, tots disposaven de ports o de riberes mínimament condicionades per a la recalada de vaixells; la seva minsa extensió territorial (...); la seva permeabilitat lingüística(...); i la seva posició estratègica respecte dels grans eixos del comerç internacional de l'època.» Per tant, segons Riera, «El reialme de Mallorca era, doncs, una construcció política fràgil, que confinava amb estats força més ferms: la Corona d'Aragó i França. La seva autonomia es perpetuaria mentre la "confederació" s'hagués d'enfrontar amb problemes més greus a la Mediterrània o a la Península Ibèrica, entretant no entrebanqués seriosament les expansions territorial i mercantil catalanes a ultramar.» En aqueix article Riera dibuixa, amb traç decidit i veu erudita, la trajectòria del Regne de Mallorca fins que, a la dècada de 1340 , es donaren les condicions propícies per a la seva reintegració a la Corona d'Aragó. La compilació es clou amb un treball esplèndid («Els jueus de Menorca a la primera meitat del segle XIV. Les seqüeles d'una relació d'identitats asimètrica»), de 2009, utilíssim no tan sols per al coneixement de la petita comunitat jueva de la Balear menor, sinó també per a la de totes les Illes Balears. I, tot plegat, amb una introducció que permet al lector contextualitzar dins un marc general tota aquella documentació que li és oferta i analitzada referida a Menorca.

En resum i concloent: només resta felicitar als editors per la seva iniciativa que, a banda d'esdevenir un merescut homenatge a la tasca del mestre, de l'historiador «de referència»-com en diuen ara- que ha estat i és Antoni Riera Melis, permet posar a l'abast del lector un aplec de treballs, majoritàriament antics però encara vigents, i que reunits permeten fornir $-\mathrm{o}$, si tant voleu, mantenir- una visió de conjunt sobre una època fonamental de la història de Mallorca. 